\title{
PERBEDAAN MOTILITAS SPERMATOZOA SAPI JANTA (frisian holstein) SETELAH PEMBERIAN CAIRAN KRISTALOID-RINGER LAKTAT
}

\author{
${ }^{1}$ Kristin Yumte \\ ${ }^{2}$ Benny Wantouw \\ ${ }^{2}$ Edwin de Queljoe
}

\author{
${ }^{1}$ Kandidat Skripsi Fakultas Kedokteran Universitas Sam Ratulangi \\ ${ }^{2}$ Bagian Biologi Fakultas Kedokteran Universitas Sam Ratulangi \\ Email: kyumte@yahoo.com
}

\begin{abstract}
Spermatozoa motility is one of the benchmarks determining Fertilisation, where energy is used for movement is influenced by energy sources such as fructose, and liquid electrolytes such as $\mathrm{Na}+, \mathrm{Ca}+, \mathrm{Cl}$-, and lactate.This study aimed to assess the motility of spermatozoa after crystalloid fluid penembahan given Ringer's lactate. The design of this study is the correlation study with a sample of 4 bull testiclesData collected by differentiating cauda epididymis of bull testicles and Ringer's lactate given crystalloid fluid is then observed under a microscope. From the research that has been done on the motility of the results obtained after administration of Ringer's lactate infusion at $56.35 \%$ while the non-provision of $52.5 \%$. Conclusion: The bull sperm have a progressive motility after having given crystalloid fluid Ringer's lactate.
\end{abstract}

Keywords: Motility, Spermatozoa, Lactate

\begin{abstract}
Abstrak: Motilitas spermatozoa merupakan salah satu tolok ukur penentu kesangupan Fertilisasi, dimana energi yang digunakan untuk pergerakannya di pengaruhi oleh sumber energi seperti fruktosa, dan cairan elektrolit seperti $\mathrm{Na}+, \mathrm{Ca}+$,Cl-, dan laktat. Penelitian ini bertujuan untuk menilai motilitas spermatozoa setelah diberikan penembahan cairan kristaloid ringer laktat. Desain penelitian ini adalah correlation study dengan jumlah sampel 4 testis sapi jantan. Data dikumpulkan dengan membeda cauda epididimis dari testis sapi jantan dan diberikan cairan kristaloid ringer laktat kemudian diamati dibawah mikroskop. Dari penelitian yang telah dilakukan di peroleh hasil motilitas setelah pemberian cairan infus ringer laktat sebesar 56,35\% sedangkan tanpa pemberian sebesar 52,5\%. Simpulan: Spermatozoa sapi jantan memiliki motilitas progresif setelah di berikan cairan kristaloid ringer laktat.
\end{abstract}

Kata kunci: Motilitas, Spermatozoa, Laktat.

Motilitas spermatozoa adalah salah satu kriteria penentu kualitas spermatozoa yang dilihat dari banyaknya spermatozoa yang bergerak progresif, dengan maksud agar sampai di dalam alat reproduksi wanita untuk fertilisasi. ${ }^{1}$ Penilaian motilitas spermatozoa sangat penting karena motilitas umumnya digunakan sebagai parameter kesanggupan membuahi. Energi untuk motilitas bersumber pada bagian ekor spermatozoa. Dimana bagian ekor spermatozoa terdiri dari dua bagian ujung (end piece). Pada bagian pangkal (middle piece) ter- dapat mitokondria yang berfungsi dalam proses metabolism dari spermatozoa dalam menghasilkan energi. Energi yang digunakan untuk motilitas spermatozoa ini berasal dari perombakan ATP (adenosine trifosfat) di dalam selubung mitokondria melalui reaksi-reaksi penguraiannya menjadi ADP (adenosin difosfat) dan AMP (adenosin monofosfat), dimana energi yang dihasilkan bagian ujung (end piece) ini akan digunakan sebagai pergerakan spermatozoa (energi mekanik). 1,2,3 $^{\text {(enert }}$

Ringer laktat merupakan cairan yang 
paling fisiologis yang dapat diberikan pada kebutuhan volume dalam jumlah besar. Ringer laktat banyak digunakan sebagai replacement therapy. Laktat yang merupakan hasil glukoneogenesis dari metabolisme karbohidrat, dimana laktat mengalami peristiwa pemecahan gula yang terjadi di dalam sitoplasma sel yang menghasilkan energi berupa ATP. ${ }^{2,3}$ Pada pergerakannya spermatozoa di pengaruhi oleh beberapa sumber energi seperti fruktosa, sorbitol, GPC (Gyceril phorporycholin), kalsium dan plasmogen serta beberapa cairan elektrolit seperti $\mathrm{Na}+, \mathrm{Ca}+, \mathrm{Cl}-$, dan laktat. Sumber energi dan cairan elektrolit ini sering ditemukan komposisinya dalam cairan krisataloid ringer laktat yang dipakai untuk menggantikan defisit cairan yang hilang. ${ }^{2,3,4}$

Dalam penelitian ini peneliti mencoba mengkaji perubahan energi untuk Motilitas dari spermatozoa yang timbul akibat penambahan cairan kristaloid ringer laktat.

\section{METODE PENELITIAN}

Penelitian ini merupakan penelitian eksperimental laboratorik, dengan menggunakan correltion study, yang menggunakan binatang percobaan sapi jantan sebagai subjek penelitian. Cairan kristaloid yang digunakan adalah cairan ringer laktat. dimana Pemberian cairan ringer laktat sebanyak 0,5 cc menggunakan spoit 5 cc dengan dua kali perlakuan dan empat kali ulangan. Hewan coba dalam penelitian ini adalah sapi jantan (Frisian Holstein) sebanyak empat ekor dan dua ekor cadangan yang diperoleh dari Rumah Potong Hewan (RPH) kelurahan bunaken Tuminting, Manado. Sampel penelitian ini di ambil secara acak dengan kriteria inklusi: sapi jantan, sehat, umur 3-4 tahun, berat badan $502-705 \mathrm{~kg}$.

\section{Desain penitian}

Jenis Penelitian yang dilakukan adalah eksperimental laboratoris dengan menggunakan correltion study. Pengambilan data dilakukan dengan cara melihat hubungan perbandingan secara langsung.

\section{Waktu dan Tempat penelitian}

Penilitian ini dilakukan di laboratorium dasar biologi Fakultas MIPA Universitas Sam Ratulangi Manado mulai bulan November sampai Desember 2012.

\section{Alat dan Bahan}

Alat yang di gunakan dalam penelitian ini yaitu: termos, termometer, tabung gelas, objek glas, cover glass, pisau kater, mikroskop cahaya dan kamera digital. Bahan yang digunakan pada penelitian ini yaitu: cairan ringer laktat yang di gunakan mempunyai komposisi sebagau berikut: Calcium clorida 0,10 g, sodium clorida 130 $\mathrm{mEq} / \mathrm{L}$, Sodium laktat $1,55 \mathrm{~g}$ dan calcium 0,99 , cairan $\mathrm{NaCl}$ fisiologis .

\section{Cara kerja}

Prosedur penelitian ini yaitu. Testis sapi yang diperoleh dari rumah potong hewan (RPH) Tuminting dibersihkan dan dimasukan kedalam tabung gelas (Toples kaca) yang diisi larutan $\mathrm{NaCl}$ fisiologis, kemudian tabung itu di masukan kedalam termos yang di beri air hagat agar suhunya tetap terjaga sekitar $36,5^{\circ} \mathrm{C}$ dan ditranspor ke laboratorium. Cairan semennya di ambil dengan membedah kauda epididimis dari testis sapi jantan dan di oleskan pada objek glass dan kemudian di tutup dengan cover glass dan untuk menilai Energi yang digunakan untuk motilitasnya di berikan penambahan cairan kristaloid ringer laktat pada objek glass yang telah dioleskan cairan semen. Setelah itu di amati motilitasnya di bawah mikroskop cahaya dengan pembesaran $40 \mathrm{X}$ sampai $400 \mathrm{X}$ per lapang pandang.

\section{Pengamatan motilitas spermatozoa}

Motilitas di lihat dari persentase spermatozoa yang bergerak maju progresif ke depan. Ditentukan secara subjektif per lapang pandang dengan mikroskop cahaya pembesaran 10x40. Lapangan pandang diperiksa secara sistematik dan motilitas setiap spermatozoa yang di jumpai di kategorikan sesuai dengan pengamatan 
apakah spermatozoa menunjukkan:

1. Ma. Gerak cepat dan maju lurus

2. Mb. Gerak lambat dan sulit maju lurus

3. Mc. Tidak bergerak maju/gerak di tempat

4. Md. Tidak bergerak.

Persentase motilitasnya di tentukan dengan rumus: ${ }^{1,5}$

Persentase motilitas:

$\frac{\text { sel sperma motil progresif }}{\text { sperma yang di amati }}$ X $100 \%$

\section{Pengamatan viabilitas spermatozoa}

Spermatozoa di lihat dari persentase spermatozoa yang mati dan persentase spermatozoa yang hidup. Spermatozoa yang hidup menunjukan ada pergerakan tetapi spermatozoa yang mati tidak ada pergerakan,persentase viabilitas ditentukan dengan rumus ${ }^{5}$

Persentase viabilitas $=$

$\frac{\text { jumlah spermatozoa hidup }}{\text { sel sperma yang di amati }}$ X 100\%

\section{Analisis Data}

Adapun metode penelitian yang digunakan adalah Rancangan Bujur sangkar latin (RBLS) dengan dua perlakuan dan empat kali ulangan, kemudian untuk mengetahui nilai rata-rata perbandingan dari perlakuan dilanjutkan dengan analisis secara statistic non-parametrik, dengan menggunakan uji $\mathrm{T}$ test dengan menggunakan softwere SPSS for windows 17.

\section{HASIL DAN PEMBAHASAN}

Perbandingan sperma hidup yang bergerak kedepan dengan konsentrasi sperma total dalam semen menunjukan persentase sperma motill progresif . Data pengamatan motilitas dan daya hidup spermatozoa sebelum dan sesudah pemberian cairan infuse Ringer Laktat yang mengandung calcium selama penelitian tertera pada Tabel 2 dan Tabel 3. Dari Tabel 2 diperoleh rerata motilitas tertinggi pada perlakuan (P2) yaitu Motilitas sesudah pemberian cairan infuse Ringer Laktat sebesar 56,35\% sedangkan Tanpa pemberian cairan Ringer laktat sebesar 52,5\%. Sedangkan untuk daya hidup spermatozoa pada perlakuan dengan konsentrasi cairan Ringer Laktat yang sama di dapatkan hasil rataan sebelum di berikan cairan infuse Ringer Laktat adalah $66,14 \%$ dan sesudah pemberian cairan Ringer Laktat adalah 330,4\%. Laktat merupakan senyawa yang dapat berubah menjadi asam piruvat dan sebaliknya.

Tabel 1. Persentase motilitas spermatozoa sebelum dan sesudah pemberian cairan infuse Ringer Laktat Sapi (Frisian Holstein) (\%).

\begin{tabular}{llll}
\hline & & \multicolumn{2}{c}{ Perlakuan } \\
\cline { 3 - 4 } No & Ulangan & P1 & P2 \\
\hline 1 & I & 50 & 60 \\
2 & II & 50 & 40 \\
3 & III & 40 & 60 \\
4 & IV & 70 & 65 \\
\hline & XY & 210 & 225 \\
& XYi & 11500 & 130,25 \\
Rerata & X & 52,5 & 56,25 \\
\hline
\end{tabular}

Keterangan: P1=Perlakuan tanpa pemberian cairan infuse RL. P2=Perlakuan sesudah pemberian cairan infuse RL.

Tabel 2: Persentase viabilitas spermatozoa sebelum dan sesudah pemberian cairan infus Ringer Laktat Sapi (Frisian Holstein) (\%).

\begin{tabular}{llll}
\hline & & \multicolumn{2}{c}{ Perlakuan } \\
\cline { 3 - 4 } No & Ulangan & P1 & p2 \\
\hline 1 & I & 70,79 & 85,88 \\
2 & II & 55,88 & 69,35 \\
3 & III & 69,45 & 80,35 \\
4 & IV & 70,02 & 84,87 \\
\hline & XY & 66,14 & 330,45 \\
& XYi & 66,53 & 82,61 \\
Rerata & X & 1785,5 & 276,4 \\
\hline
\end{tabular}

Keterangan: P1=Perlakuan tanpa pemberian cairan infus RL, P2=Perlakuan sesudah pemberian cairan infuse RL. 
Tabel 3. Perbedaan Motilitas dan viabilitas spermatozoa sapi sebelum dan setelah pemberian cairan Ringer Laktat.

\begin{tabular}{lllllll}
\hline & & & $\mathbf{N}$ & Correlation & Sig. \\
\hline P1 & $\begin{array}{l}\text { Motilitas spermatozoa } \\
\text { Spermatozoa }\end{array}$ & \& & Viabilitas & 9 & .060 & .879 \\
\hline
\end{tabular}

\begin{tabular}{llccll}
\hline & Mean & N & Std. Deviation & $\begin{array}{l}\text { Std. Error } \\
\text { Mean }\end{array}$ \\
\hline P2 & Motilitas spematozoa & 1.44 & 9 & .527 & .176 \\
& Viabilitas spermatozoa & 1.22 & 9 & .441 & .147 \\
\hline
\end{tabular}

Keterangan: P1=Perlakuan sebelum pemberian cairan RL. P2=Perlakuan setelah pemberian RL.

Perubahan itu terjadi dalam peristiwa glikolisis (Peristiwa pemecahan gula yang terjadi di sitoplasma sel). Motilitas atau daya gerak spermatozoa merupakan kemampuan gerak maju progresif spermatozoa, sebagai salah satu indikasi dalam menentukan kualitas spermatozoa, dan daya fertilitas spermatozoa sangat di tentukan oleh jumlah total spermatozoa yang hidup dan bergerak aktif ke depan.

Hasil pengujian dengan menggunakan uji T sampel bebas pada Tabel 3, didapatkan rerata motilitas spermatozoa setelah pemberian cairan Ringer Laktat adalah sebesar $1,44 \%$ dan rerata viabilitas spermatozoa setelah pemberian cairan Ringer Laktat adalah sebesar $1,22 \%$ artinya ratarata motilitas dan viabilitas spermatozoa sesudah pemberian cairan Ringer laktat adalah tidak sama, dengan demikian angka perbedaan rerata (mean difference) sebesar 0,222, dalam penilaian paired samples correlation, motilitas dan viabilitas berkorelasi sebesar 0,060, Artinya hubungan dua kondisi kuat dan signifikan karena nilai probabilitasnya sebesar $0,000<0,05$ dari hasil yang diperoleh dapat disimpulkan bahwa Viabilitas berpengaruh terhadap motilitas spermatozoa.,

Pada penelitian ini spermatozoa yang di gunakan adalah spermatozoa dari sapi (Fristian Holstein), Penelitian ini dilakukan karena banyak pendapat mengenai pengaruh pemberian cairan Ringer Laktat terhadap kualitas dari pada spermatozoa yaitu khususnya motilitas dan viabilitasnya.

Dari hasil Analisis Uji $T$ sampel Bebas menunjukan bahwa terdapat hubungan yang signifikan antara Viabilitas dan motilitas dari pada spermatozoa pada saat di berikan cairan Ringer Laktat. Perbedaannya dapat terlihat pada Tabel 3 yaitu di peroleh hasil yang didapatkan ratarata motilitas spermatozoa setelah pemberian cairan Ringer Laktat adalah sebesar $1,44 \%$ dan rata-rata viabilitas spermatozoa setelah pemberian cairan Ringer Laktat adalah sebesar $1,22 \%$ artinya rata-rata motilitas dan viabilitas spermatozoa sesudah pemberian cairan Ringer laktat adalah tidak sama ${ }^{.7,9}$

\section{Viabilitas spermatozoa setelah pemberi- an cairan infuse Ringer Laktat}

Persentase viabilitas spermatozoa dapat di hitung dengan melihat reaksi spermatozoa terhadap zar warna tertentu, dimana spermatozoa yang hidup tidak berwarna sedangkan spermatozoa yang mati akan menyerap warna .Pada Tabel 3. Persentase spermatozoa hasil pengamatan menunjukan daya hidup dari spermatozoa setelah di berikan Cairan Ringer Laktat adalah 276,4\%, semen yang baik memiliki persentase viabilitas diatas 50\%. Dikatakan bahwa Persentase viabilitas spermatozoa berhubungan positif terhadap integritas membran spermatozoa banyak yang bagus, maka nilai viabilitas spermatozoa banyak pula. 


\section{Motilitas spermatozoa setelah pemberian cairan infuse Ringer laktat}

Motilitas menurut WHO (world health organization) dihitung dengan melihat spermatozoa yang bergerak kedepan secara cepat dan spermatozoa yang bergerak lambat. $^{7}$

Hasil. Uji T Sampel Bebas pada perlakuan pemberian cairan Ringer Laktat menunjukan persentase yang sangat baik, dan bisa di katakan bahwa kadar laktat dapat mempengaruhi motilitas dari pada spermatozoa. Pada penelitian ini kadar laktat yang terdapat dalam cairan Ringer Laktat mempunyai peran yang penting dalam motilitas dari spermatozoa, dimana telah di sebutkan terlebih dahulu bahwa bagian ekor spermatozoa terdiri dari dua bagian ujung (end piece). Pada bagian pangkal (middle piece) terdapat mitokondria yang telah memanjang yang berfungsi dalam kegiatan metabolism spermatozoa. Ekor spermatozoa (end piece) mengandung semua sarana untuk motiletas, Hal ini dimana ekor spermatozoa memberikan pergerak progresif kepada spermatozoa dengan gelombang-gelombang dan bagian tengah ekor (middle piece) merupakan tempat yang memberi energi untuk kehidupan dan pergerakan spermatozoa oleh prosesproses metabolisme yang berlangsung didalam mitokondria ${ }^{3,6,1}$

Hal ini di sebabkan karena energi yang digunakan untuk motilitas spermatozoa berasal dari perobakan ATP didalam sel tubuh mitokondria melalui reaksi-reaksi penguraiannya menjadi ADP (Adenosin diphospat) dan AMP (adenosin monophospat). Energi yang dihasilkan ini akan dipakai sebagai pergerakan (energi mekanik). ${ }^{3}$

Sebagian besar motilitas dan viabilitas spermatozoa dapat hidup dan bergerak progresif bila ada penambahan cairan Ringer Laktat. Laktat yang merupakan hasil ahir dari proses glukoneogenesis dalam metabolime karbohidrat melalui reaksi oksidasi asam piruvat dalam satu siklus krebs. Salah satu golongan karbohidrat, yaitu disakarida berperan menggantikan posisi air pada permukaan membran plasma sel. Selain itu karbohidrat juga dapat berperan sebagai substrat sumber energi bagi spermatozoa selama proses preservasi, sehingga dapat memperpanjang daya hidupnya. Laktat dan maltosa merupakan karbohidrat golongan disakarida yang terdiri atas dua unit monosakarida, yakni satu unit glukosa dan satu unit galaktosa untuk laktat serta dua unit glukosa untuk maltosa, yang semuanya dapat di metabolisme oleh spermatozoa untuk menghasilkan energi berupa ATP (Adenosin TriPhosphate ). ${ }^{6,3}$

Selanjutnya spermatozoa memanfaatkan ATP sebagai sumber energi dalam proses pergerakannya sehingga spermatozoa dapat tetap motil dan sekaligus semakin mempertahankan daya hidupnya ${ }^{3}$

Motilitas spermatozoa juga berkaitan erat degan Viabilitas spermatozoa artinya nilai persentase motilitas spermatozoa yang rendah akan menghasilkan nilai persentase viabilitas yang rendah. Begitu juga sebaliknya nilai persentase motilitas yang tinggi akan menghasilkan nilai persentase yang tinggi. Hal ini berarti nilai motilitas spermatozoa berpengaruh terhadap nilai viabilitas dari spermatozoa, Persentase motilitas spermatozoa yang tinggi mempunyai daya gerak yang progresif dan menghasilkan gerakan massa sehingga menunjukan bahwa spermatozoa masih banyak hidup dan menghasilkan persentase viabilitas yang tinggi setelah diberikan cairan Ringer Laktat.

\section{SIMPULAN}

Spermatozoa sapi jantan (frisian holstein) setelah di berikan cairan kristaloid Ringer Laktat memiliki motilitas yang progresif dan mempunyai kemampuan daya hidup yang baik. Terdapat hubungan yang signifikan dari spermatozoa sapi jantan (frisian holstein) setelah di berikan cairan kristaloid Ringer Laktat dibandingkan sebelum di berikan.

\section{SARAN}

Diharapkan agar para pria bisa mem- 
peroleh asupan sumber energi yang di peroleh dari cairan Kristaloid dan lebih memberikan pengaruh pada kualitas spermatozoa yang lebih baik. Diharapkan penggunaan cairan kristaloid bisa sesuai indikasinya,agar tidak terjadi efek samping atau komplikasi yang membahayakan organ tubuh lainnya.

\section{DAFTAR PUSTAKA}

1. Tjipto WB. Kajian Infertil Pria di Laboratorium Infertil Andrologi Puslitbang Sistem dan Kebijakan Kesehatan Surabaya Tahun 2005-2008 [homepage on the Internet]. Nodate [cited 2013 Jan 18]. Available from: http:// www.gogle,laboratoriuminfertileandrolog, 60176.

2. Sari NS. Pengaruh suhu dan lama Thawing terhadap kualitas spermatozoa sapi Fries Holland. Malang; Universitas Islam Negeri 2008 [homepage on the Internet]. Nodate [cited 2012 Oct 7]. Available from: http;/google.spermatozoa sapi.com/2012.

3. Setyadi DA. Organ Reproduksi dan Kualitas Sperma Mencit( Mus musculus) yang Mendapat Pakan Tambahan Kemangi (Ocium basilicum) Segar. Bogor: IPB, 2006.

4. Muklis MRP. Pengaruh Pemberian Cairan Ringer Laktat dibandingkan $\mathrm{NaCl}$ 0,9\% Terhadap Keseimbangan AsamBasa pada Pasien Sectio caesaria dengan Anastesi Regional. UNDIP. Semarang.
2006. [homepage on the Internet]. Nodate [cited 2013 Jan 18]. Available from: http://www.google.com.

5. Mumu IM. Viabilitas semen Sapi Simental Yang Dibekukan Menggunakan Krioproktektan Gliserol, Universitas Tandulako, Sulawesi Tengah; Juni 2009 [homepage on the Internet]. Nodate [cited 2012 Nov 17]. Available from: https://www.google.com/motilitas,viabilit as=Metabollisme+les\%ISSN;0854-641X

6. Rodel WV, Granner KD, Murray KR. Biokimia Harper (Edisi Keduapuluh Tujuh). 'Jakarta: EGC, 2009; Hal.159.

7. Djauhari T. Pengaruh pemberian Fosfolipid Terhadap Kualitas Spermatozoa Manusia, Malang 2008 [homepage on the Internet]. diakses 14 januari 2013). Available from: https://www.google. com/search3AenUS\%3Aofficial\&channel $=$ np\&biw $=1024 \& b i h=630 \& q=$ metabolism e+laktat\&oq=Metabollisme+les\%3B..0.01 c.1.96L7PLAR7vc.

8. Karina. Triman JR. Materi Biokimia. Glukoneogenesis [homepage on the Internet]. Nodate [cited 2013 Jan 18] Available from: http://www.metabolisme. karbohidrat.com.

9. Budiono H, Sarwono J. Statistik Terapan, Aplikasi untuk Riset, Skripsi, Tesis dan Disertase; PT elex media kompotindo; Palembang; 2012

10. http://ariscahkeduang.blogspot.com/2013/ 01/inseminasi-buatan.html (diakses 14 Januari 2013) 